\title{
Downregulation of connexin 43 in nasopharyngeal carcinoma cells is related to promoter methylation
}

\author{
Zong-Chun Yi *, Hong Wang, Guang-Yao Zhang, Bing Xia
}

Department of Biological Engineering, Beijing University of Aeronautics and Astronautics, 37 Xueyuan Road, Beijing 100083, PR China

Received 17 October 2006; accepted 1 November 2006

Available online 15 February 2007

\author{
KEYWORDS \\ Connexin 43; \\ Gap junction intercellular \\ communication; \\ Methylation; \\ Nasopharyngeal \\ carcinoma
}

\begin{abstract}
Summary Down-regulation of Cx43 expression had been shown to occur in nasopharyngeal carcinoma cells. The present study was undertaken to estimate if methylation of the promoter region in $\mathrm{C} \times 43$ gene was responsible for the repression of $\mathrm{C} \times 43$ expression in the CNE-1 nasopharyngeal carcinoma cells. Calcein transfer and lucifer yellow transfer were detected to evaluate gap junction intercellular communication (GJIC) in CNE-1 cells. It was found that the control CNE-1 cells showed no fluorescent dye transfer. After treatment with DNA methyltransferase inhibitor 5-aza-CdR, fluorescent dye transfer between cells became obvious. RT-PCR and Western blot were performed to determine the expression of $\mathrm{Cx} 43$ gene. The control CNE-1 cells showed a low expression level of $\mathrm{Cx} 43$, whereas 5 -aza-CdR-treated $\mathrm{CNE}-1$ cells showed an enhanced level of Cx43 expression. Methylation-sensitive restriction enzyme and PCR analysis showed that the methylation of the $\mathrm{Cx} 43$ gene promoter region occurred in $\mathrm{CNE}-1$ cells. In addition, treatment with 5 -aza-CdR inhibited the growth (including anchorage-independent growth) of CNE-1 cells, and resulted in an accumulation of cells in G0/G1 phase. These results indicate the promoter methylation as an important role in inactivation of $C_{X 43}$ in CNE-1 cells.

(c) 2006 Elsevier Ltd. All rights reserved.
\end{abstract}

\section{Introduction}

Nasopharyngeal carcinoma (NPC) is a type of head and neck cancer. It occurs sporadically in the west but is endemic in southern China and Southeast Asia. ${ }^{1}$ In the year 2000, a total of 64,798 new cases were registered worldwide, and more than $80 \%$ of those were reported from these areas. ${ }^{2}$ In

\footnotetext{
* Corresponding author. Tel.: +86108233 9422; fax: +86108231 5554.

E-mail address: yizc@buaa.edu.cn (Z.-C. Yi).
}

southern China, nasopharyngeal carcinoma (NPC) is the third most common form of malignancy amongst men, with incidence rates of between 25 and 30 per 100,000 persons per year. ${ }^{1}$ Intercellular communication through gap junction (GJIC) plays a significant role in maintaining tissue homeostasis by exchanging small molecules, such as sugars, nucleotides, and second messengers, which has long been proposed as a mechanism to regulate growth control, development and differentiation. ${ }^{3}$ Dysfunctional GJIC has been also recognized as being involved in carcinogenesis. ${ }^{3,4}$ It has been showed that down-regulation of connexin 43 
(Cx43) expression and dysfunctional GJIC occur in nasopharyngeal carcinomas tissues and cells, ${ }^{5-8}$ suggesting that dysfunctional GJIC plays a key role in naopharyngeal carcinogenesis.

The methylation within promoters is associated with transcriptional silencing of tissue-specific genes, $\mathrm{X}$ chromosome-linked gene inactivation, and some repetitive elements. ${ }^{9,10}$ It has been observed that normally unmethylated $\mathrm{CpG}$ islands can become aberrantly methylated or hypermethylated in neoplastic cells, and this has been suggested to be an important and common mechanism for transcriptional silencing of many tumor suppressor genes. ${ }^{11}$ Methylation has been reported to occur in the promoter region of $\mathrm{Cx} 43$ gene in various tumor cells, which is responsible for suppression of Cx43 expression and loss of Cx43-mediated GJIC. ${ }^{12,13}$ The present study was undertaken to estimate whether methylation of the promoter region in Cx43 gene was responsible for the repression of $\mathrm{Cx} 43$ expression in the CNE-1 nasopharyngeal carcinoma cells.

\section{Materials and methods}

\section{Cell culture}

CNE-1 cells were cultured in Dulbecco's modified Eagle's medium (DMEM, Life Technologies Inc.) supplemented with $10 \%$ fetal bovine serum (FBS) (HyClone), $100 \mathrm{U} / \mathrm{ml}$ penicillin (Sigma) and $100 \mu \mathrm{g} / \mathrm{ml}$ streptomycin (Sigma) in a humidified atmosphere containing $5 \% \mathrm{CO}_{2}$ at $37^{\circ} \mathrm{C}$.

\section{5-Aza-2'-deoxycitidine Treatment}

5-Aza-2'-deoxycitidine (5-aza-CdR) was obtained from Sigma. The CNE-1 cells were plated in dishes at a density of $5 \times 10^{5}$ cells $/ \mathrm{ml}$. When the cells became confluent, 5-aza$\mathrm{CdR}$ at the different final concentration $(0.25 \mu \mathrm{M} \sim 25 \mu \mathrm{M})$ was added to the medium. After treatment with 5-azaCdR for $24 \mathrm{~h}$, the cells were washed with phosphatebuffered saline (PBS) and fresh medium was added. Seventy-two hours later, the treated cells were used for the following assays.

\section{Gap junction intercellular communication assays}

Lucifer yellow and calcein transfer assays were used to measure GJIC in confluent CNE-1 cells treated with 5-azaCdR. These techniques were carried out as follows:

\section{Calcein transfer assay}

GJIC was measured using calcein transfer assay as previously described. ${ }^{14}$ Briefly, for loading with calcein acetoxymethyl ester (calcein AM) (Fluka/Sigma), donor cells were trypsinized with $0.25 \%$ trypsin solution, suspended in culture medium, centrifuged, re-suspended in $2 \mathrm{ml}$ of staining solution ( $5 \mu \mathrm{M}$ calcein $\mathrm{AM}$, and $0.3 \mathrm{M}$ glucose), and fluorescence-labeled for $30 \mathrm{~min}$ at $37^{\circ} \mathrm{C}$. The cells were then washed with PBS three times, and added to a monolayer culture of unstained recipient cells. After incubation for $3 \mathrm{~h}$, these co-cultures were trypsinized, suspended in PBS, and analyzed with a Becton Dickinson FACScan. The mem- brane-permeable calcein $A M$ is hydrolyzed by intracellular nonspecific esterase and the resulting green fluorescent hydrophilic calcein is then trapped inside the cells. Therefore, gap junctions are permeable for calcein. In flow cytometry analysis, two peaks of calcein fluorescent density will appear in the obtained diagram. The right one represents the donor cells, and the left one means the recipient cells. If the cells demonstrate functional GJIC, the left peak will shift to right in co-cultured cells compared with the mixture of donor cells and recipient cells without incubation at $37^{\circ} \mathrm{C}$.

\section{Lucifer yellow transfer}

GJIC was also measured by microinjection of the fluorescent dye Lucifer yellow $\mathrm{CH}(10 \%$ in $0.33 \mathrm{M} \mathrm{LiCl})$ into selected cells by means of a micromanipulator and a micro-injector system (Olympus). Five minute after injection, the number of fluorescent cells around each injected single cell, which was loaded with the dye, was scored. Ten individual cells were injected per dish and means of number of fluorescent neighboring cells were calculated. Images were taken with an Olympus fluorescent microscope.

\section{Reverse transcription-polymerase chain reaction (RT-PCR)}

Total RNA was extracted using Trizol Total RNA Minipreps Classic Kit (Sangon, Shanghai, China) as described in the manufacturer's instructions. The RNA quantity was identified from the absorbance at $260 \mathrm{~nm}$. First strand cDNA was synthesized using $25 \mu \mathrm{g}$ total RNA by M-MuLV reverse transcriptase (Sangon, Shanghai, China) in a $100 \mu$ reaction system.

PCR was carried out using $10 \mu 1$ of CDNA in a $50 \mu$ reaction with UNOII Thermocycler (Biometra). The sense primer for human CX43 was $5^{\prime}$-TGAGCAGTCT GCCTTTCGTTG-3', and the antisense primer was $5^{\prime}$-CCATCAGTTT GGGCAACCTTG$3^{\prime}$. The expected amplified fragment for Cx43 was $219 \mathrm{bp}$. As an internal control, the sense primer for $\beta$-actin gene was $5^{\prime}$-TGGACTTCGA GCAAGAGATGG-3', and the antisense primer was $5^{\prime}$-ATCTCCTTCTGCATCCTGTCG-3'. The expected amplified fragment for $\beta$-actin was $289 \mathrm{bp}$. The amplification reactions were initiated by a denaturation step for 4 min at $95^{\circ} \mathrm{C}$ and then subjected to 28 cycles of $95^{\circ} \mathrm{C}$ for $1 \mathrm{~min}, 60^{\circ} \mathrm{C}$ for $45 \mathrm{~s}$, and $72^{\circ} \mathrm{C}$ for $45 \mathrm{~s}$. The amplified DNA products were separated on $2 \%$ agarose gel, stained with ethidium bromide, visualized and photographed with ImageMaster Video Documentation System (Pharmacia Biotech).

\section{Western blotting}

Western blotting were performed to assay the protein level of Cx43. Briefly, the cells were lysed with $20 \%$ SDS containing $1 \mathrm{mM}$ phenylmethylsulfonyl fluoride (Sigma), $1 \mathrm{mM}$ leupeptin (Sigma), $1 \mathrm{mM}$ antipain (Sigma), $0.1 \mathrm{M}$ aprotinin (Sigma), $0.1 \mathrm{mM}$ sodium orthovanadate (Sigma) and $5 \mathrm{mM}$ sodium fluoride. After sonicating the lysates, protein concentrations were determined using the BCA protein assay kit (Beyotime Biotechnology). Proteins were separated on 
12.5\% SDS polyacrylamide gels and transferred to PVDF membranes (Pall Gelman Laboratory). The separated proteins were reacted sequentially for $1 \mathrm{~h}$ at room temperature with primary antibodies for Cx43 (Zymed) and $\beta$-actin (Sig$\mathrm{ma}$ ), followed by fluorescein-conjugated secondary antibody, detected with ECF chemifluorescence Western blotting Kit (Amersham Biosciences), visualized and obtained photos with a Storm 860 Phosphorlmager system (Amersham Pharmacia Biotech).

\section{Methylation-sensitive restriction enzymes and PCR}

Genomic DNA was isolated from CNE-1 cells by a Classic Genomic DNA Isolation Kit (Sangon, Shanghai, China) as described in the manufacturer's manual. Methylation status of promoter region was determined by digestion with methylation-sensitive restriction enzyme, followed by a PCR method. ${ }^{15}$ Briefly, genomic DNA was digested completely with restriction endonucleases EcoRV, methylation-insensitive $\mathrm{Mspl}$, methylation-sensitive Hpall or methylation-sensitive Hhal (Sangon, Shanghai, China). For the double digestion, DNA was digested overnight with EcoRV $(6 \mathrm{U} / \mu \mathrm{g})$ at $37^{\circ} \mathrm{C}$, and then a part of the EcoRV-digested DNA was subsequently digested overnight with Mspl $(6 \mathrm{U} / \mu \mathrm{g})$, Hpall $(6 \mathrm{U} / \mu \mathrm{g})$ or Hhal $(6 \mathrm{U} / \mu \mathrm{g})$ at $37^{\circ} \mathrm{C}$. To determine the target fragment $(-1512$ to -1233$)$ of promoter region in human Cx43 gene, in which there are $12 \mathrm{CpG}$ dinucleotides, $1 \mathrm{Mspl} / \mathrm{Hpall}$ site and 2 Hhal sites, $100 \mathrm{ng}$ of digested DNA was amplified by $P C R$. The sense primer for the target fragment was $5^{\prime}$ TGCAACATTTGGGCCCAG- $3^{\prime}$, and the antisense primer was $5^{\prime}$-TCTGGTAGACACCGTTCC-3'. PCR was performed with at first an initial denaturation at $95^{\circ} \mathrm{C}$ for $4 \mathrm{~min}$, followed with 35 cycles of $95^{\circ} \mathrm{C}$ for $1 \mathrm{~min}, 62^{\circ} \mathrm{C}$ for $1 \mathrm{~min}$, and $72^{\circ} \mathrm{C}$ for $2 \mathrm{~min}$, and a final extension for $72{ }^{\circ} \mathrm{C}$ for $7 \mathrm{~min}$. The amplified DNA products were separated on $2 \%$ agarose gel, stained with ethidium bromide, visualized and photographed with ImageMaster Video Documentation System (Pharmacia Biotech). PCR products (280 bp) will be found at the promoter having methylated status when digested with Hpall or Hhal. No products will be found at the promoter having unmethylated status when digested with Hpall or Hhal. All of the samples digested with Mspl will have no products. To rule out the possibility of incomplete digestion, all samples were digested twice with each of the enzymes in independent experiments. PCR amplifications from each of the duplicate digests were repeated at least twice to ensure reproducibility of the results.

\section{Cell growth analysis}

For measuring the effect of 5-aza-CdR on cell growth, CNE-1 cells were seeded and cultured in six-well plates at $1 \times 10^{5}$ cells/well. When the cells were confluent, the medium was replaced with fresh medium containing 5aza-CdR at different concentrations. After treatment with 5 -aza-CdR for $24 \mathrm{~h}$, the cells were washed with PBS and fresh medium was added. Seventy-two hours later, the cell number in each well was counted using a haemocytometer.

\section{Anchorage-independent growth assay}

In each plate, one hundred cells in $2.5 \mathrm{ml}$ of $0.33 \%$ agarose medium were plated on the top of $2.5 \mathrm{ml}$ pre-hardened $0.5 \%$ agarose medium. After incubation at $37^{\circ} \mathrm{C}$ for 1 day, the medium containing 5 -aza-CdR at different concentrations was added on the top of the agar, and then incubation continued. Ten days later, the plates were dried at $37^{\circ} \mathrm{C}$ for 1 day and anchorage-independent colonies of cells were stained with $1 \mathrm{mg} / \mathrm{ml}$ of 2-(p-iodophenyl)-3-(nitrophenyl)5-phenyltetrazolium chloride (Sigma). The number of colonies in each plate was counted. The cloning efficiency was defined as the number of colonies per one hundred plated cells. The values from three independent experiments were averaged to obtain the final cloning efficiency of anchorage independence.

\section{Cell cycle analysis}

Cells were collected by centrifugation, fixed by $70 \%$ ethanol and re-suspended at $1 \times 10^{6}$ cells $/ \mathrm{ml}$ in propidium iodide (PI) staining buffer $(0.1 \%$ sodium citrate, $0.1 \%$ Triton- $X$ 100 , and $50 \mu \mathrm{g} / \mathrm{ml} \mathrm{PI}$ ) and were treated with $1 \mathrm{mg} / \mathrm{ml}$ RNase at room temperature for $30 \mathrm{~min}$. Cell-cycle histograms were generated after analysis of PI-stained cells with a Becton Dickinson FACScan. For each culture, at least $1.5 \times 10^{4}$ events were recorded. Histograms generated by FACS were analyzed by ModFit Cell Cycle Analysis Software V2.0 to determine the percentage of cells in each phase $(\mathrm{G} 1, \mathrm{~S}$, and $\mathrm{G} 2 / \mathrm{M})$.

\section{Results}

\section{5-aza-CdR induces restoration of GJIC}

5-aza-CdR is an inhibitor of DNA methyltransferase. In this study, we determined the changes of GJIC in CNE-1 cells after treatment with 5-aza-CdR. Fluorescent dye calcein transfer through gap junction was determined using flow cytometry to evaluate functional gap junctions (Fig. 1A). As expected, in control CNE-1 cells, after co-culture of recipient cells and donor cells for $3 \mathrm{~h}$, the recipient cell peak (the right one of black peaks) only slightly shifted to right compared with the recipient cell peak (the right one of gray peaks) of mixed cells without co-culture, which suggests the control CNE-1 cells showed no dye transfer and no functional gap junctions. After CNE-1 cells were treated with 5 -aza-CdR at the concentration of $25 \mu \mathrm{M}$, the recipient cell peak obviously shifted to right, indicating that the treatment with 5-aza-CdR restored GJIC.

In order to further validate the effects of 5-aza-CdR upregulating $\mathrm{GJIC}$, fluorescent dye Lucifer yellow $\mathrm{CH}$ was injected into a single cell, and lucifer yellow transfer through gap junction was observed using fluorescence microscope (Fig. 1B). It was observed that the number of communicating cells per injected cell was $10.0 \pm 1.0$ cells in 5 -aza-CdRtreated cells, while there was almost no communicating cell in control CNE-1 cells. These results indicate that 5-aza-CdR treatment can restore GJIC of CNE-1 cells. 

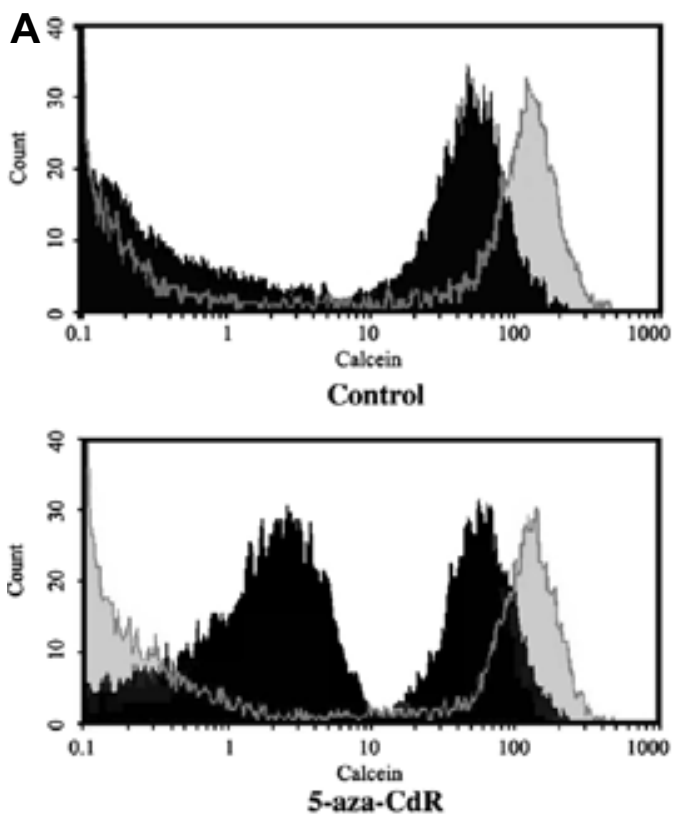

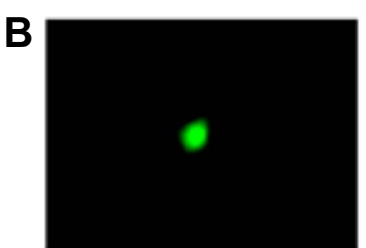

Control

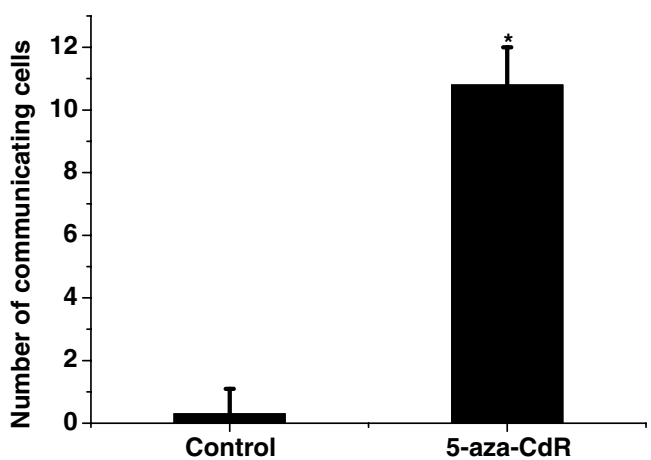

Figure 1 Effects of 5 -aza-CdR on GJIC of CNE-1 cells. (A) Calcein transfer in control and 5-aza-CdR-treated CNE-1 cells. After CNE-1 cells were treated with 5-aza-CdR, one set of cells were fluorescence-labeled with calcein-AM as donor cells. Then the donor cells were added to a monolayer culture of unstained recipient cells and cultured for $3 \mathrm{~h}$ at $37^{\circ} \mathrm{C}$. After that, the transfer of calcein form donor cells (right black peak) to recipient cells (left black peak) was analyzed by flow cytometry. The gray peaks indicated the mixture of the donor cells (right peak) and recipient cells (left peak) without co-culture at $37^{\circ} \mathrm{C}$. Here represent one of three independent experiments. (B) Lucifer yellow transfer in control and 5-aza-CdR-treated CNE-1 cells. The confluent CNE-1 cells were exposed to 5-aza$\mathrm{CdR}$ at $25 \mu \mathrm{M}$ for $24 \mathrm{~h}$. The cells were then washed with phosphate-buffered saline and fresh medium was added. Seventy-two hours later, GJIC was measured by microinjection of the fluorescent dye Lucifer yellow $\mathrm{CH}$. The data represent means \pm SD of three independent experiments. "Significantly different from control $(p<0.01)$.
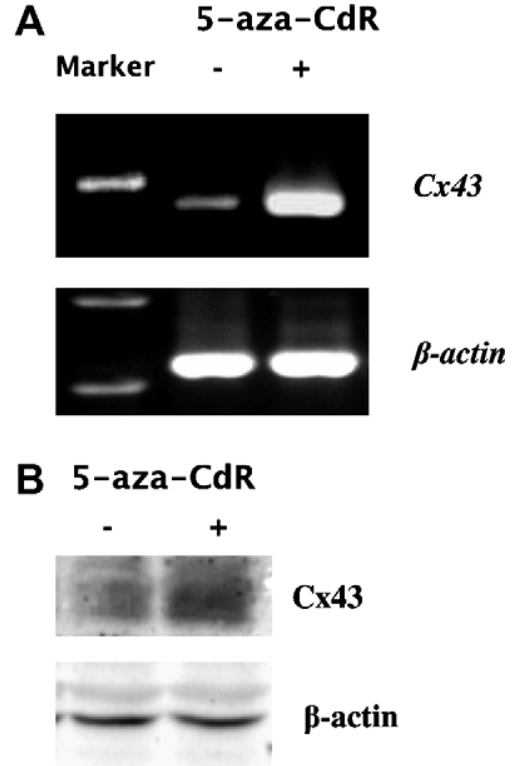

Figure 2 Effects of 5-aza-CdR on expression of Cx43 in CNE-1 cells. The confluent CNE-1 cells were exposed to 5 -aza-CdR at concentration of $25 \mu \mathrm{M}$ for $24 \mathrm{~h}$. The cells were then washed with phosphate-buffered saline and fresh medium was added. Seventy-two hours later, the mRNA levels (A) and protein levels (B) of $\mathrm{Cx} 43$ gene were determined by RT-PCR and Western blotting analysis, respectively. Here represent one of three independent experiments.

\section{5-aza-CdR enhances the expression of $\mathrm{Cx} 43$}

Cx43 protein is one type of general sub-unit of gap junction semi-channel. To evaluate the mechanism of GJIC restoration by 5 -aza-CdR, it was detect whether treatment with 5-aza-CdR altered the expression of $\mathrm{Cx} 43$ gene. RT-PCR was performed to determine the mRNA level of $\mathrm{C} \times 43$ gene. We observed that the control CNE-1 cells showed low mRNA expression level of $\mathrm{Cx} 43$, whereas 5-aza-CdR-treated CNE-1 cells showed an enhanced level of Cx43 transcript (Fig. 2A). Protein expression of Cx43 was also analyzed by Western blot. As shown in Figure 2B, 5-aza-CdR up-regulated $\mathrm{C} \times 43$ protein levels. These results suggest that the silencing of Cx43 gene and deficiency in GJIC in CNE-1 cells might relate to DNA methylation.

\section{Methylation status in the promoter region of $\mathrm{Cx} 43$ gene}

In order to further clarify methylation of the $\mathrm{Cx} 43$ gene promoter region in $\mathrm{CNE}-1$ cells, we used the methylation-sensitive restriction enzyme/PCR. A 280 bp DNA fragment is successfully amplified from EcoRV-digested genomic DNA from CNE-1 cells (Fig. 3). When EcoRV-digested genomic DNA was further digested with methylation-insensitive restriction enzyme Mspl, no PCR product was found. However, when EcoRV-digested genomic DNA was further digested with methylation-sensitive restriction enzyme Hpall or Hhal, the PCR products could be observed. These results indicate that the silencing of $\mathrm{C} \times 43$ gene expression 


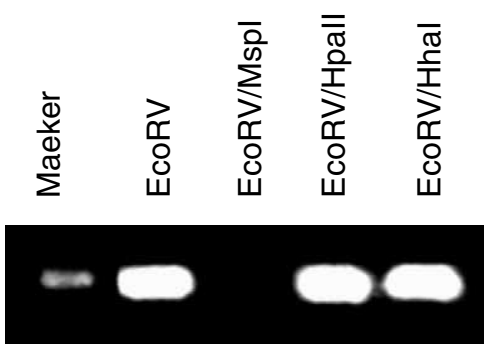

Figure 3 Cx43 promoter methylation status analyzed with Methylation-sensitive restriction enzyme/PCR in CNE-1 cells. After genomic DNA was digested with EcoRV, the EcoRVdigested DNA was subsequently digested overnight with Mspl, Hpall or Hha I. Then, PCR for Cx43 was carried out. EcoRV, DNA only digested with EcoRV. EcoRV/Mspl, DNA digested with EcoRV and Mspl. EcoRV/Hpall, DNA digested with EcoRV and Hpall. EcoRV/Hhal, DNA digested with EcoRV and Hhal.

in CNE-1 cells correlates with methylation of the gene promoter region.

\section{5-aza-CdR inhibits the growth of CNE-1 cells}

We further determined the effects of increasing concentrations of 5 -aza-CdR on cell growth. After confluent CNE-1 cells were treated with 5 -aza-CdR for $24 \mathrm{~h}$, the medium was replaced. Seventy-two hours later, the cell number in each well was counted. It was observed that the growth of CNE-1 cells was inhibited in a concentration-dependant manner (Fig. 4A). 5-aza-CdR at concentration of $25 \mu \mathrm{M}$ caused over $50 \%$ decrease of cell growth but without obvious cytoxicity.

Flow cytometry analysis was conducted to analyze the cell cycle of CNE-1 cells treated with $25 \mu \mathrm{M}$ 5-aza-CdR. The treatment induced G0/G1-phase cell cycle arrest of CNE-1 cells concomitant with a decrease in $S$ phases (Fig. 4C). The percentage of cells in G0/G1 phase in 5-aza-CdR -treated cells increased to $60.45 \%$ from $45.30 \%$ compared with the control cells, whereas the percentage of cells in $\mathrm{S}$ phase decreased to $22.82 \%$ from $37.46 \%$, respectively. The number of cells in G2/M phase showed no difference.

The effect of 5 -aza-CdR on anchorage-independent growth of CNE-1 cells in soft agar was also detected. After CNE-1 cells were plated in soft agar and cultured for $24 \mathrm{~h}$, the medium containing 5-aza-CdR was added on the top of the agar. After a 10 days culture, the anchorage-independent growth of the cells was showed in Figure 4B. The control cells formed colonies in soft agar with high cloning efficiency $(89 \%)$, whereas the treatment with 5 -aza-CdR from $0.25 \mu \mathrm{M}$ to $25 \mu \mathrm{M}$ resulted in a concentration-dependent decrease, and $25 \mu \mathrm{M}$ 5-aza-CdR-treated CNE-1 cells showed cloning efficiency only $25 \%$.

\section{Discussion}

Loss of GJIC has been linked to aberrant proliferation and an enhanced neoplastic phenotype. Many human tumors have been reported to be deficient in expression of the connexin (CX) genes and GJIC, and $C x$ genes have been suggested as tumor suppressor genes. ${ }^{3,4}$ However, mutations in $C x$ genes
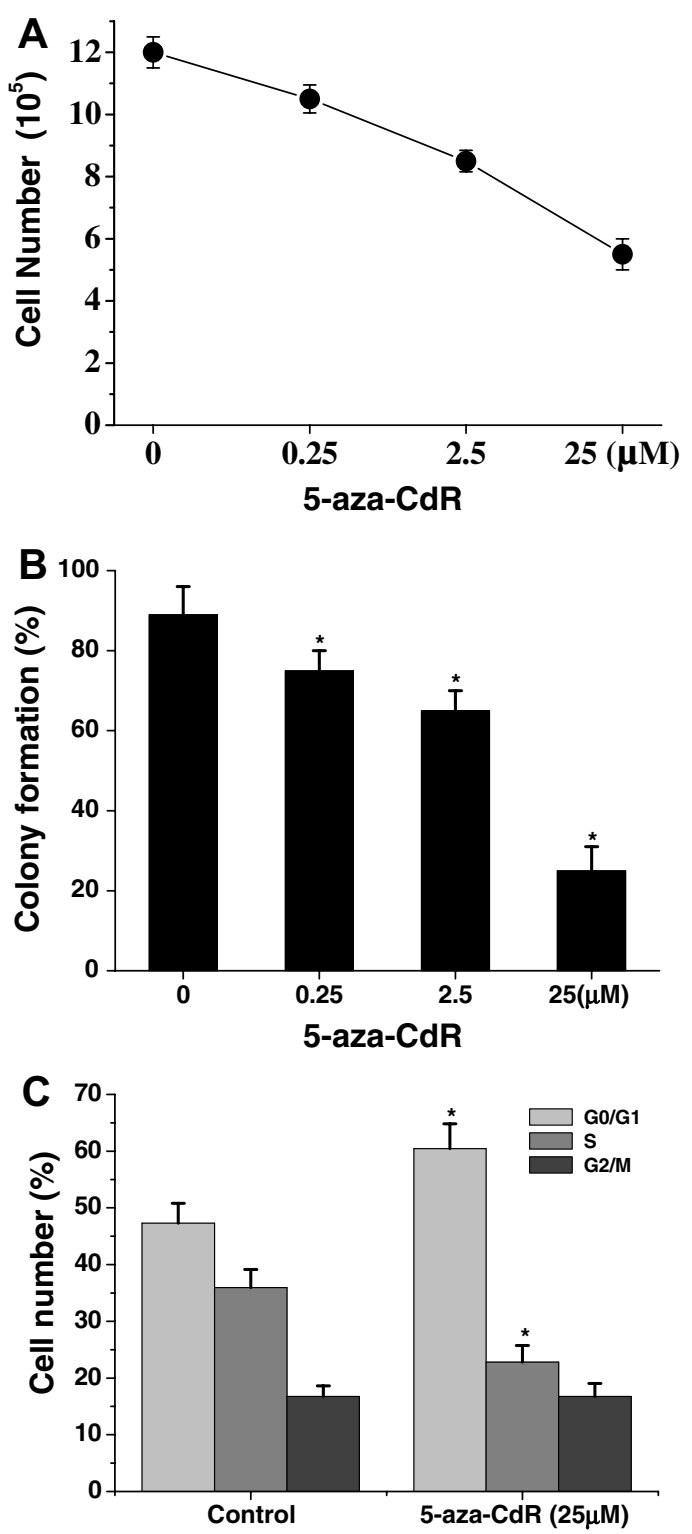

Figure 4 The Changes of cell growth and Cell cycle of CNE1 cells after treatment with 5-aza-CdR. (A) Effects of 5-aza$\mathrm{CdR}$ on growth of CNE-1 cells. After treatment with 5-aza$\mathrm{CdR}$ at indicated concentrations for $24 \mathrm{~h}$, the medium was replaced. Seventy-two hours later, the cell number in each well was counted. Data represent the mean and SD from three independent experiments. (B) The effect of 5-aza-CdR on anchorage-independent growth of CNE-1 cells. CNE-1 cells were plated in soft agar 100 cells pre plate. After 1 day, the medium containing 5 -aza-CdR at indicated concentrations was added on the top of the agar. Ten days later, the colony formation in soft agar was assayed. Data represent the mean and SD from three independent experiments. " $p<0.01 \mathrm{vs.}$ solvent control. (C) Cell cycle analysis of CNE-1 cells after treated with 5-aza-CdR. After the confluent CNE-1 cells were exposed to 5 -aza-CdR at $25 \mu \mathrm{M}$ for $24 \mathrm{~h}$, the medium was refreshed. Seventy-two hours later, the cells were stained with propidium iodide, and 15,000 cells of each sample were analyzed under FACScan. Data represent the mean and SD from three independent experiments. " $p<0.01$ vs. solvent control. 
including Cx43 were found to be rare events in carcinogenesis. ${ }^{16}$ It is well established that promoter methylation can result in decreased expression of tumor suppressor genes such as p16, p15, RB, VHL, hMLH-1, APC and BRCA1 genes, and contributing to increased tumorigenicity in a variety of human cancers. ${ }^{11}$ Previous studies has shown that cellspecific transcription of $\mathrm{C} \times 32$ and $\mathrm{C} \times 43$ in hepatic cells is controlled by promoter methylation, ${ }^{17}$ suggesting that the methylation within promoters might involve in transcriptional inhibition of connexin genes in cancer cells. Downregulation of Cx43 expression and dysfunctional GJIC had been shown to occur in nasopharyngeal carcinoma tissues and cells. ${ }^{5-8}$ In our present study, treatment with 5-Az$\mathrm{CdR}$ induced the re-expression of $\mathrm{Cx} 43$ at mRNA and protein levels, and restored the capacity of cell-cell communication in $\mathrm{CNE}-1$ cells. These results suggested that the silencing of $\mathrm{C} \times 43$ gene depended on the methylation of the promoter region in CNE-1 cells. In order to confirm this possibility, we estimated whether the methylation occurred in the promoter region of $\mathrm{C} \times 43$ gene in CNE-1 cells using methylation-sensitive restriction enzymes and PCR method. The results demonstrated that methylation of the $\mathrm{C} x 43$ promoter region occurred in CNE-1 cells. This indicated that the methylation of the promoter region was an important factor to induce the repression of the $\mathrm{C} \times 43$ gene.

The promoter of the human $\mathrm{C} \times 43$ genes has been well cloned. ${ }^{18}$ Several functional cis-acting elements, including AP-1 and AP-2 response elements, Sp1 response element and estrogen response elements, have been described in the human $\mathrm{C} \times 43$ promoters. ${ }^{19}$ The AP- 1 sites in the human Cx43 promoter function positively since phorbol ester treatment of human uterine myometrial cells increased $\mathrm{C} \times 43$ expression within $6-8 \mathrm{~h}$ and mutation of the most proximal AP- 1 site reduced the response. ${ }^{20}$ The human $\mathrm{C} x 43$ promoter contains several half-palindromic estrogen-responsive elements (EREs) that enhance Cx43 transcription in the presence of estrogen. ${ }^{21}$ Thus, we suggest that aberrant trans-acting factors binding with promoter region by meththylation may be responsible for the aberrant $\mathrm{Cx} 43$ gene transcription.

The methylation at the promoter and proximal transcribed region has been reported to be responsive for the repression of $\mathrm{Cx} 43$ gene and other connexin genes in other various tumor cells. It has been reported that aberrant Cx43 mRNA expression was regulated by promoter methylation in non-small cell lung cancer, and this aberrant expression was correlated with nodal micrometastasis. ${ }^{12}$ King et al has shown that treatment of Cx43-negative clones from HeLa cells with methylation inhibitor 5-aza-2'-deoxycytidine resulted in expression of $\mathrm{Cx} 43$, suggesting that methylation of the $\mathrm{Cx} 43$ gene promoter, or a gene regulating this promoter, might be responsible for suppression of $\mathrm{Cx} 43$ expression and loss of Cx43-mediated GJIC in HeLa cells. ${ }^{13}$ Hypermethylation in the promoter region is a mechanism for the $C \times 32$ gene repression in human renal cell carcinoma cells. ${ }^{22,23} \mathrm{C} \times 26$ is a structural component of gap junctions expressed in breast epithelial cells. Expression levels of Cx26 are reduced in many breast tumors. Tan et al have reported that methylation of the promoter region of the $C \times 26$ gene is likely to be an important mechanism in modulating the expression of $\mathrm{Cx} 26$ in breast cancer. ${ }^{24}$ Another report showed that downregulation of Cx 26 in human lung cancer was also related to promoter methylation. ${ }^{25}$ These results suggested that promoter methlyation might be a common mechanism for repression of connexin genes in various tumor cells. However, we cannot exclude the possibility that some other factors are involved in the repression of the $C x$ genes. A recent study has showed that methylation was probably not involved as a primary mechanism of $\mathrm{C} \times 26$ regulation in human esophageal cancer cell lines. ${ }^{26}$ It has been well revealed that another important mechanism that mediates the regulation of gene transcription, either activation or repression, is the acetylation status of nuclear histones by histone acetyltransferases (HAT) and histone deacetylase (HDAC). ${ }^{27,28}$ In general, histone acetylation by HAT favors the open chromatin structure that is more transcriptionally active, while deacetylation by HDAC favors chromatin condensation that is prone for repression of gene transcription. Recently, a HDAC-dependent mechanism was reported to be responsible for the transcriptional repression of Cx43 in prostate cancer cells, which affect Sp1 and Ap1 transcription factors together with the coactivator/adaptor p300/ CBP and possibly other factors to regulate $\mathrm{C} \times 43$ gene transcription. ${ }^{29}$. In addition, extracellular matrix protein fibronectin and overexpression of estrogen receptor-alpha gene has been shown to suppress the expression of $\mathrm{C} \times 26$ in alveolar epithelial cells and endometrial carcinoma cells, respectively. ${ }^{30,31}$ Further studies are required to dissect whether these pathways regulate the expression of $C x$ genes in various cancer cells.

Cx43 and other connexin protein have been indicated to function as a tumor suppressor. ${ }^{3,4}$ Transfection of connexin 43 decreases neoplastic potential as evidenced by attenuated anchorage-independent growth. ${ }^{13}$ We further determined the effects of increasing concentrations of 5-azaCdR on cell growth. Our results show that together with increasing gap junction communication and $\mathrm{C} \times 43$ expression, 5-aza-CdR significantly decreases the cell proliferation and anchorage-independent growth. The inhibition of cell proliferation and anchorage-independent growth is likely due to a block of cell cycle progression, because 5-aza$\mathrm{CdR}$ increased the percentage of cells in the G0/G1 coinciding with a significant decrease in the number of cells in the $S$ phase. In fact, previous studies have indicated that the reestablishment of gap junctions with the restoration of gap junctional communication affects the phenotype of transformed or tumor cells involved in cell cycle regulation. Transfection and overexpression of $\mathrm{Cx} 43$ genes reverted phenotypically transformed dog kidney epithelial cells to a flat morphology and restored the cells sensitive to density-dependent inhibition of proliferation with their G1and S-phase duration almost doubled. ${ }^{32}$ Another study showed that overexpression of $\mathrm{C} \times 43$ suppressed proliferation of human osteosarcoma U2OS cells through inhibition of the cell cycle transition from G1 to S phase. ${ }^{33}$ Tolbutamide, a sulfonylurea compound, has been shown to enhance gap junction permeability in the poorly coupled C6 glioma cells with an increase of $\mathrm{C} \times 43$ expression. ${ }^{34}$ The increase in communication is concurrent with the inhibition of the rate of proliferation due to a block of the progression of C6 glioma cells through the S phase of the cell cycle.

Overall, it seems that the down-regulation of $\mathrm{Cx} 43$ gene mediated through the methylation of the promoter regions in nasopharyngeal carcinoma cells. Treatment of DNA meth- 
yltransferase inhibitor 5 -aza-CdR could induce restoration of GJIC and an inhibition of tumor phenotype of CNE-1 cells.

\section{Acknowledgement}

This study was supported by the National Natural Science Foundation of China (Project no. 30400092).

\section{References}

1. Yu MC, Yuan JM. Epidemiology of nasopharyngeal carcinoma. Semin Cancer Biol 2002;12:421-9.

2. Ferlay J, Bray F, Pisani P, Parkin DM. GLOBOCAN 2000: cancer incidence, mortality and prevalence worldwide, Version 1.0. IARC CancerBase No. 5. Lyon: IARC Press, 2001.

3. Loewenstein WR, Kanno Y. Intercellular communication and the control of tissue growth: lack of communication between cancer cells. Nature 1966;209:1248-9.

4. Trosko JE, Chang CC, Upham BL, Tai MH. Ignored hallmarks of carcinogenesis: stem cells and cell-cell communication. Ann NY Acad Sci 2004; 1028:192-201.

5. Fan SQ, Zhou M, Xiang Q, Wang JR, Xiong W, Wang R, et al. In situ expression of connexins in various carcinomas. Ai Zheng 2003;22:686-90. [Article in Chinese].

6. Han LQ, Gao J, Dong HY. Studies on the gap junctional intercellular communication of human nasopharyngeal carcinoma cells and effect of Rll. Zhonghua Zhong Liu Za Zhi 1994;16:345-8. [Article in Chinese].

7. Shen Z, Lin J, Li M, Zeng Q. Study on the expression of connexin 43 in human nasopharyngeal carcinoma. Lin Chuang Er Bi Yan Hou Ke Za Zhi 2002;16:402-3., p. 406, [Article in Chinese].

8. Xiang Q, Fan SQ, Li J, Tan C, Xiang JJ, Zhang QH, et al. Expression of connexin43 and connexin45 in nasopharyngeal carcinoma. Ai Zheng 2002;21:593-6. [Article in Chinese].

9. Bird AP. CPG-rich island and the function of DNA methylation. Nature 1986;321:2009-13.

10. Singal R, Ginder GD. DNA methylation. Blood 1999;93:4059-70.

11. Esteller M. Dormant hypermethylated tumor suppressor genes: questions and answers. J Pathol 2005;205:172-80.

12. Chen JT, Cheng YW, Chou MC, Sen-Lin T, Lai WW, Ho WL, et al. The correlation between aberrant connexin 43 mRNA expression induced by promoter methylation and nodal micrometastasis in non-small cell lung cancer. Clin Cancer Res 2003;9:4200-4.

13. King TJ, Fukushima LH, Donlon TA, Hieber AD, Shimabukuro KA, Bertram JS. Correlation between growth control, neoplastic potential and endogenous connexin43 expression in HeLa cell lines: implications for tumor progression. Carcinogenesis 2000;21:311-5.

14. Yi Z-C, Liu Y-Z, Li H-X, Yin Y, Zhuang F-Y, Fan Y-B, et al. Tellimagrandin I enhances gap junctional communication and attenuates the tumor phenotype of human cervical carcinoma HeLa cells in vitro. Cancer Lett 2006;242:77-87.

15. Singer-Sam J, Grant M, LeBon JM, Okuyama K, Chapman V, Monk $M$, et al. Use of a Hpall-polymerase chain reaction assay to study DNA methylation in the Pgk-1 CpG island of mouse embryos at the time of X-chromosome inactivation. Mol Cell Biol 1990;10:4987-9.

16. Omori Y, Krutovskikh V, Mironov N, Tsuda H, Yamasaki H. Cx32 gene mutation in a chemically induced rat liver tumour. Carcinogenesis 1996;17:2077-80.
17. Piechocki MP, Burk RD, Ruch RJ. Regulation of connexin32 and connexin43 gene expression by DNA methylation in rat liver cells. Carcinogenesis 1999;20:401-6.

18. De Leon JR, Buttrick PM, Fishman GI. Functional analysis of the connexin43 gene promoter in vivo and in vitro. $J$ Mol Cell Cardiol 1994;26:379-89.

19. Trosko JE, Ruch RJ. Cell-cell communication in carcinogenesis. Front Biosci 1998;3:208-36.

20. Geimonen E, Jiang W, Ali M, Fishman GI, Garfield RE, Andersen J. Activation of protein kinase $C$ in human uterine smooth muscle induces connexin- 43 gene transcription through an AP-1 site in the promoter sequence. J Biol Chem 1996;271: 23667-74.

21. Yu W, Dahl G, Werner R. The connexin43 gene is responsive to oestrogen. Proc R Soc Lond [Biol] 1994;255:125-32.

22. Hirai A, Yano T, Nishikawa K, Suzuki K, Asano R, Satoh H, et al. Down-regulation of connexin 32 gene expression through DNA methylation in a human renal cell carcinoma cell. Am J Nephrol 2003;23:172-7.

23. Yano T, Ito F, Kobayashi K, Yonezawa $Y$, Suzuki K, Asano $\mathrm{R}$, et al. Hypermethylation of the $\mathrm{CpG}$ island of connexin 32, a candiate tumor suppressor gene in renal cell carcinomas from hemodialysis patients. Cancer Lett 2004;208:137-42.

24. Tan LW, Bianco T, Dobrovic A. Variable promoter region CpG island methylation of the putative tumor suppressor gene connexin26 in breast cancer. Carcinogenesis 2002;23: 231-6.

25. Chen Y, Huhn D, Knosel T, Pacyna-Gengelbach M, Deutschmann I, Petersen I. Downregulation of connexin26 in human lung cancer is related to promoter methylation. Int $J$ Cancer 2005; 113:14-21.

26. Loncarek J, Yamasaki H, Levillain P, Milinkevitch S, Mesnil M. The expression of the tumor suppressor gene connexin 26 is not mediated by methylation in human esophageal cancer cells. Mol Carcinog 2003;36:74-81.

27. Wolffe AP. Histone deacetylase: a regulator of transcription. Science 1996;272:371-2.

28. Kuo $M H$, Allis CD. Roles of histone acetyltransferases and deacetylases in gene regulation. Bioessays 1998;20: 615-26.

29. Hernandez M, Shao Q, Yang XJ, Luh SP, Kandouz M, Batist G, et al. A histone deacetylation-dependent mechanism for transcriptional repression of the gap junction gene cx43 in prostate cancer cells. Prostate 2006;66:1151-61.

30. Guo Y, Martinez-Williams C, Yellowley CE, Donahue HJ, Rannels DE. Connexin expression by alveolar epithelial cells is regulated by extracellular matrix. Am J Physiol Lung Cell Mol Physiol 2001;280:191-202.

31. Saito T, Tanaka R, Wataba K, Kudo R, Yamasaki H. Overexpression of estrogen receptor-alpha gene suppresses gap junctional intercellular communication in endometrial carcinoma cells. Oncogene 2004;23:1109-16.

32. Chen SC, Pelletier DB, Ao P, Boynton AL. Connexin43 reverses the phenotype of transformed cells and alters their expression of cyclin/cyclin-dependent kinases. Cell Growth Differ 1995;6:681-90.

33. Zhang Y-W, Morita I, Ikeda M, Ma KW, Murota S. Connexin43 suppresses proliferation of osteosarcoma U2OS cells through post-transcriptional regulation of p27. Oncogene 2001;20: 4138-49.

34. Sánchez-Alvarez R, Tabernero A, Sánchez-Abarca LI, Orfao A, Giaume C, Medina JM. Proliferation of C6 glioma cells is blunted by the increase in gap junction communication caused by tolbutamide. FEBS Lett 2001;509:202-6. 